\title{
ALEXANDRE DUMAS FILS, Théâtre complet
}

\section{Ida Merello}

\section{OpenEdition Journals}

\section{Edizione digitale}

URL: https://journals.openedition.org/studifrancesi/32063

DOI: 10.4000/studifrancesi.32063

ISSN: 2427-5856

\section{Editore}

Rosenberg \& Sellier

\section{Edizione cartacea}

Data di pubblicazione: 1 août 2020

Paginazione: 427

ISSN: 0039-2944

\section{Notizia bibliografica digitale}

Ida Merello, «AleXandre dumas fILs, Théâtre complet», Studi Francesi [Online], 191 (LXIV | II) | 2020, online dal 01 septembre 2020, consultato il 18 septembre 2021. URL: http://journals.openedition.org/ studifrancesi/32063 ; DOI: https://doi.org/10.4000/studifrancesi.32063

\section{Questo documento è stato generato automaticamente il 18 septembre 2021.}

\section{(c) $(1) \odot$}

Studi Francesi è distribuita con Licenza Creative Commons Attribuzione - Non commerciale - Non opere derivate 4.0 Internazionale. 


\title{
ALEXANDRE DUMAS FILS, Théâtre complet
}

\author{
Ida Merello
}

\section{NOTIZIA}

ALEXANDRE DUMAS FILS, Théâtre complet, t. I, éd. L. Sabourin, Paris, Classiques Garnier 2019, $901 \mathrm{pp}$.

1 Era davvero improcrastinabile l'edizione critica, almeno del Théâtre complet, di Alexandre Dumas fils, ma ci voleva l'erudizione, l'abilità di interpretazione dei manoscritti e anche la passione letteraria di Lise Sabourin per portare a termine un simile impegno. Il secondo volume, data l'enorme mole di materiale, è ancora in lavorazione, e un'occhiata alla grafia dei manoscritti e alla quantità di cancellature fa capire lo sforzo che quest'edizione richiede, soprattutto per l'edizione dell'École des matrones, recuperato direttamente dal manoscritto. Per le altre pièces, l'A. si è basata sull'edizione curata da Dumas fils nel 1886, più volte riproposta fino al 1947, servendosi per il controllo dei testi principalmente del fondo manoscritto lasciato in dono nel 1951 alla Nationale da Mme Balachowsky-Petit.

2 La prefazione, filologicamente impeccabile, è anche calda e animata. L'A. mostra infatti la fitta interrelazione tra vita e opera, l'impulso creatore mosso dall'autobiografia, che suggerisce gli intrighi e i caratteri dei personaggi. Sono le passioni amorose a suscitare le pièces di maggior successo, ma la stessa sofferenza e l'affetto su cui si basa il rapporto con il padre nutriranno sia romanzi autobiografici che pièces teatrali. Nello stesso tempo Dumas fils è anche, come lo definisce l'A., un «D'Artagnan de salon», che, pur commettendoli a sua volta, vorrebbe raddrizzare i torti, usando la penna come la spada, per mostrare l'ipocrisia di una società per cui il matrimonio è un investimento finanziario, ma poco redditizio. Abilissimo nel giocare con i sentimenti del pubblico, utilizza nel testo scritto la prefazione e le note per prolungare l'effetto suscitato sul palcoscenico. Non vuole concludere le sue opere col trionfo dell'amore femminile, ma, come già suo padre, studiare tutte le sfaccettature possibili del rapporto uomo/donna, in una relazione ai cui capi sono l'amore e il denaro. L'A. legge le sue ventotto pièces 
come una quête grazie alla quale Dumas fils, in maniera prefreudiana, lavora sulle sue ossessioni e affetti per liberarsi dai sensi di colpa verso coloro, donne abbandonate e bambini illegittimi, cui ha inflitto le proprie stesse torture.

3 L'A. analizza con finezza anche il meccanismo teatrale, che passa attraverso tutti i generi: dramma, commedia, teatro borghese, esotico, a tesi, raggiungendo l'apice dell'essenzialità drammatica. Dumas inizia con un'entrata a effetto dominata da un caso di coscienza che coinvolge lo spettatore, prosegue con una serie di malintesi e depistaggi, fino a un grande scioglimento in due tempi: il primo con tutta l'apparenza della verità, fino a quando non viene contraddetto.

4 Tutta la carriera artistica è seguita con uguale attenzione, e l'A. presenta il giornalista, come il romanziere e autore teatrale. La morte della cortigiana Marie Duplessis, con cui Dumas aveva intrattenuto un'appassionata relazione, gli fa scrivere d'un getto il romanzo La Dame aux camélias, nel 1847. Nel 1849, è in soli otto giorni che trasforma il romanzo per il teatro. Per ragioni storiche (il colpo di Stato, l'avvento dell'impero di Napoleone III) la serata della prima sarà ritardata, ma il successo del 1852 consacra definitivamente l'autore. La sua vita sentimentale, peraltro, come quella di autore, non conosce battute d'arresto. Ne dà testimonianza l'ampia e minuziosa bibliografia, seguita da tre indici preziosi: oltre a quello dei nomi, l'elenco in ordine cronologico di tutte le opere, e quello dei personaggi del suo teatro.

5 Il volume comprende L'École des matrones, Le Bijou de la reine, Atala, La Dame aux camélias. Ogni opera è preceduta da un'introduzione e seguita dall'apparato critico. Particolarmente imponente quello della Dame aux camélias, con un fitto confronto coi manoscritti. Oltre all'apparato critico, sono pubblicati anche gli spartiti della messa in musica di Atala da parte di A. Varney, e della Dame aux camélias di É. Montaubry. 